\title{
Assessment of Congenital Vascular and Organ Anomalies in Subjects With Thalidomide Embryopathy Using Non-Contrast Magnetic Resonance Angiography
}

\author{
Julius Matthias Weinrich, MD; Rudolf Beyer, MD; Lennart Well, MD; \\ Enver Tahir, MD; Maria Lindemann, MD; Undine Wilke; \\ Gerhard Adam, MD; Peter Bannas, MD; Gunnar K. Lund, MD
}

\begin{abstract}
Background: To determine the type and frequency of vascular and organ malformations in adults with thalidomide embryopathy (TE) using non-contrast magnetic resonance angiography (MRA) and to assess the effect of the observed malformations on renal function.

Methods and Results: The institutional ethics committee approved this prospective study and written informed consent was given by all 78 subjects ( 50 females) with TE (mean age: $55 \pm 1.1$ years), who were examined by non-contrast MRA at $3 T$. ECG-triggered balanced turbo field echo images of the chest, abdomen and pelvis were obtained in coronal and sagittal orientations. Two observers assessed the frequency of vascular and organ malformations. Serum creatinine and estimated glomerular filtration rate (eGFR) were obtained to assess renal function. In 58 subjects, 99 vascular anomalies were observed, including 68 arterial (69\%) and 31 venous anomalies (31\%); 15 patients had 16 abdominal organ malformations including 12 kidney anomalies and 4 cases of gallbladder agenesis. Most vascular anomalies affected the renal vessels $(n=66,67 \%)$ or supraaortic arteries $(n=28,28 \%)$. Serum creatinine and eGFR revealed normal renal function in all subjects.
\end{abstract}

Conclusions: Vascular and organ anomalies occurred in a high number of subjects with TE without evidence of renal dysfunction. Information about the presence of malformations may be important for future surgical interventions in subjects with TE.

Key Words: Non-contrast magnetic resonance imaging; Thalidomide; Vascular and organ abnormalities

$\mathbf{T}$ halidomide is an immunomodulatory drug that led to one of the most dramatic congenital disasters in medical history. Available without prescription, thalidomide was advertised as a sedative drug to treat anxiety, nausea and morning sickness. ${ }^{1}$ Maternal intake of this drug between 1958 and 1963 resulted in 8,000-12,000 infants with thalidomide embryopathy (TE), mainly in Europe and Japan. ${ }^{2}$ Dysmelia is a characteristic feature of TE, which includes malformations of the upper limb and ranges from deformation of the thumb and fingers to absence of the entire upper limb. In Germany, around 2,300 of 5,000 infants with TE are still alive and now in their $50 \mathrm{~s}^{3}$ Despite the well-known teratogenic effects, thalidomide is currently still prescribed to treat various diseases because of its immunomodulatory and anti-inflammatory properties. These diseases include multiple myeloma and erythema nodosum leprosum, which is an inflammatory complication of leprosy. Recently, new cases of TE were

\section{Editorial p 2250}

registered in Brazil, particularly in areas with endemic leprosy and where the dispensing of thalidomide is difficult to control. ${ }^{4}$ Therefore, TE is not only a medical care issue for aging subjects in the Northern Hemisphere but also a present health threat for young families in the Southern Hemisphere.

A recent clinical study revealed more cardiovascular events in adults with TE compared with the normal population and those authors postulated a possible vascular impairment related to TE. ${ }^{5}$ The frequency and type of vascular and organ malformations was assessed in a pilot study by Tajima et al, who reported anomalies of the vascular system in 6 of 22 subjects (27\%) with TE. ${ }^{6}$ However, their study was limited by the relative small sample size, precluding a reliable estimation of anomaly frequencies,

Received April 11, 2018; revised manuscript received April 25, 2018; accepted May 29, 2018; released online July 10 , 2018 Time for primary review: 15 days

Department of Diagnostic and Interventional Radiology and Nuclear Medicine, University Hospital Hamburg Eppendorf, Hamburg (J.M.W., L.W., E.T., G.A., P.B., G.K.L.); Department of Anesthesia, Schoenklinik, Hamburg (R.B., M.L.); and Philips Healthcare, Hamburg (U.W.), Germany

Mailing address: Gunnar Konrad Lund, Professor, MD, Department of Diagnostic and Interventional Radiology, University Hospital Hamburg Eppendorf, Martinistr. 52, 20246 Hamburg, Germany. E-mail: glund@uke.de

ISSN-1346-9843 All rights are reserved to the Japanese Circulation Society. For permissions, please e-mail: cj@j-circ.or.jp 
and by the use of a suboptimal imaging technique (unenhanced whole-body computed tomography) for evaluation of small arteries and veins.

Magnetic resonance angiography (MRA) using time-offlight and phase-contrast techniques is a well-established method for depicting the arterial and venous vasculature without the need for intravenous contrast media, which can be problematic in TE subjects with dysmelia. ${ }^{7}$ The additional advantages of balanced field turbo echo MRA are high spatial resolution and large scan volume, which enables imaging of the entire thorax and abdomen without patient or coil reallocation during the scan. ${ }^{8}$

The purpose of this study was to determine the type and frequency of vascular and organ malformations in adults with TE using non-contrast MRA and to assess the effect of the observed malformations on renal function.

\section{Methods}

\section{Subjects}

The institutional review board approved this prospective study and all subjects provided written informed consent. The 78 subjects, who were born between January 1958 and August 1963, included 50 females and 28 males with a mean age of $55 \pm 1.1$ years who were examined between February 2016 and October 2017. All subjects had anomalies of the upper extremities and were recognized by the German Contergan Foundation as having TE. Information about the presence of diabetes type II and arterial hypertension was available in $73(94 \%)$ and $71(91 \%)$ of the subjects, respectively; 14 subjects had diabetes type II (19\%) and $28(39 \%)$ suffered from arterial hypertension. Subjects were asymptomatic for thoracic or abdominal vessel or organ malformations. Serum creatinine and estimated glomerular filtration rate (eGFR) data were available for 71 subjects $(91 \%)$. Serum creatinine was defined as normal with $<1.5 \mathrm{mg} / \mathrm{dL}$ for men and $<1.4 \mathrm{mg} / \mathrm{dL}$ for women. ${ }^{9}$ eGFR was defined as normal with $>90 \mathrm{~mL} / \mathrm{min} / 1.73 \mathrm{~m}^{2} .9$ Morning spot urine sample was obtained in 39 subjects $(50 \%)$ to analyze proteinuria. The urine albumin-to-creatinine ratio was categorized as normo- $(<30 \mathrm{mg} / \mathrm{g})$, micro(30 to $300 \mathrm{mg} / \mathrm{g}$ ) or macro-albuminuria $\left(>300 \mathrm{mg} / \mathrm{g}\right.$ ). ${ }^{9}$

\section{Classification of Upper Limb Dysmelia and Eye, Ear or Facial Anomalies}

Subjects with TE were classified into 3 groups based on the extent of upper limb dysmelia according to the cephalocaudal sequence of malformation: ${ }^{10} 23$ subjects $(29 \%)$ had dysmelia of the hand, ranging from minimal change with hypotrophic or absent thenar muscles to an absent thumb or absence of several fingers; 30 subjects ( $38 \%$ ) had anomalies restricted to the forearm, varying from absence of the radius in the presence of the ulnar to total absence of the forearm with a normal proximal upper limb; 25 subjects $(32 \%)$ had dysmelia of the upper arm with a dysplastic humerus and glenoid resulting in phocomelia with residual fingers. Information about eye, ear and face anomalies was retrieved from medical records; 7 subjects suffered from eye muscle paralysis; 12 subjects had auditory organ damage, including narrow internal auditory meatus ( 2 uniand 3 bilateral), anotia (4), aplasia of the internal auditory meatus (3), aplasia of the vestibule (2). Of the 12 subjects with anomalies of the auditory organ, $6(50 \%)$ had hearing loss. A total of 3 subjects had facial deformities: 1 subject had paralysis of the 7 th cranial nerve; 1 subject had

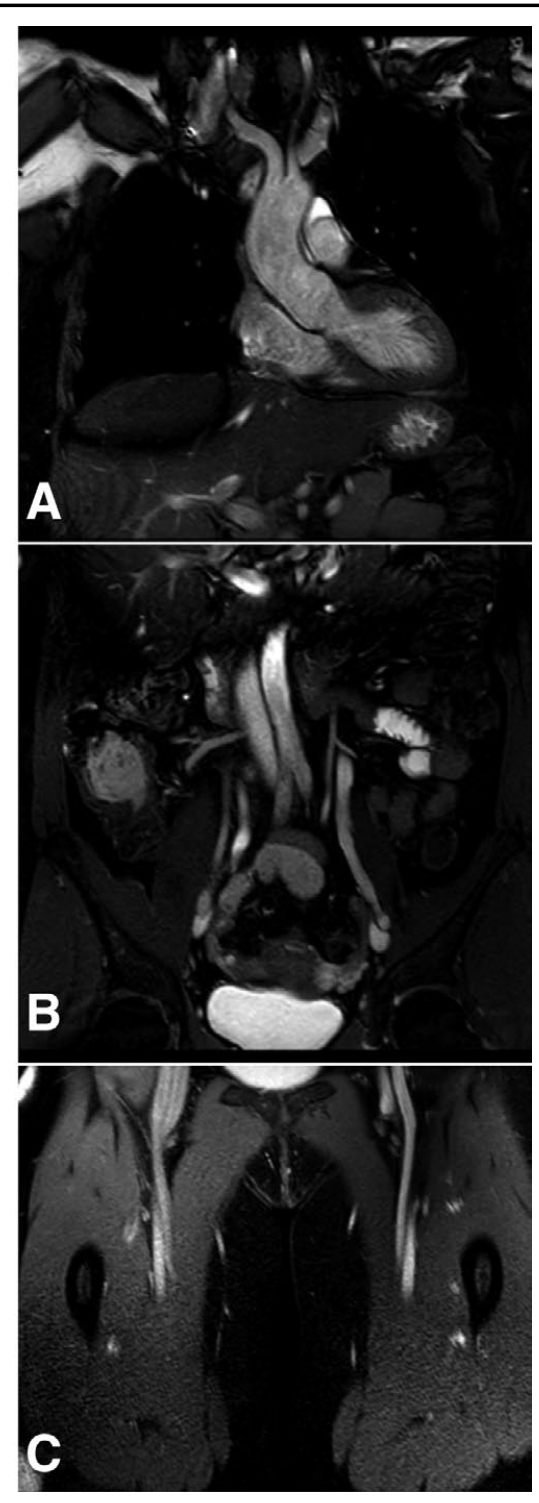

Figure 1. Non-contrast coronal MRA of thoracic (A), abdominal (B) and pelvic $(\mathbf{C})$ vessels and organs in a subject with thalidomide embryopathy.

combined eye muscle paralysis and narrow internal auditory meatus with hearing loss; 1 subject had facial deformities and anotia, resulting in 21 subjects with TE and eye, ear or facial damage.

\section{Non-Contrast MRA}

Non-contrast MRA was performed using a 3T MR system equipped with a 16-channel coil $(3.0 \mathrm{~T}$ Achieva with Sense XL torso coil, Philips Medical Systems, Best, The Netherlands). The coil size was $60 \times 55.8 \times 7.4 \mathrm{~cm}$ and covered the chest, abdomen and pelvis; 2 torso coils were used in larger subjects. Scout images were obtained in the axial, coronal and sagittal orientations. ECG-gated non-contrast 2D balanced field turbo echo imaging with sensitivity encoding (SENSE) images were acquired in the sagittal and coronal orientations (Figure 1). Breath-hold images were obtained at end-diastole to minimize motion artifacts. 


\begin{tabular}{|c|c|c|c|c|}
\hline \multirow{2}{*}{ A. Frequency of anomaly } & \multirow{2}{*}{ Vascular } & \multicolumn{2}{|c|}{ Organ } & \multirow{2}{*}{$\begin{array}{c}\text { Vascular or } \\
\text { organ }^{\mathrm{a}}\end{array}$} \\
\hline & & Renal & Gallbladder & \\
\hline No anomaly & $20(26)$ & $66(85)$ & 74 (95) & $16(21)$ \\
\hline 1 anomaly & $28(36)$ & $11(14)$ & $3(4)$ & $28(36)$ \\
\hline 2 anomalies & $22(28)$ & $1(1)$ & $1(1)$ & $22(28)$ \\
\hline 3 anomalies & $6(8)$ & 0 & 0 & $7(9)$ \\
\hline 4 anomalies & $1(1)$ & 0 & 0 & $4(5)$ \\
\hline 5 anomalies & $1(1)$ & 0 & 0 & 0 \\
\hline 6 anomalies & 0 & 0 & 0 & $1(1)$ \\
\hline Sum & \multicolumn{4}{|c|}{$78(100)$} \\
\hline B. Vascular anomaly & Renal & Supraaortic & Other & Sum \\
\hline Arterial & $38(38)$ & $28(28)$ & $2(2)$ & $68(69)$ \\
\hline Venous & $28(28)$ & 0 & $3(3)$ & $31(31)$ \\
\hline Sum & $66(67)$ & $28(28)$ & $5(5)$ & $99(100)$ \\
\hline
\end{tabular}

Data are number $(\mathrm{n})$ and percentage (\%). aSum of subjects with combinations of vascular and organ anomalies. A subject with 3 anomalies could either have 1 vascular and 2 organ anomalies or 2 vascular anomalies and 1 organ anomaly. The subject with 6 anomalies had 5 vascular and 1 organ anomalies. TE, thalidomide embryopathy.
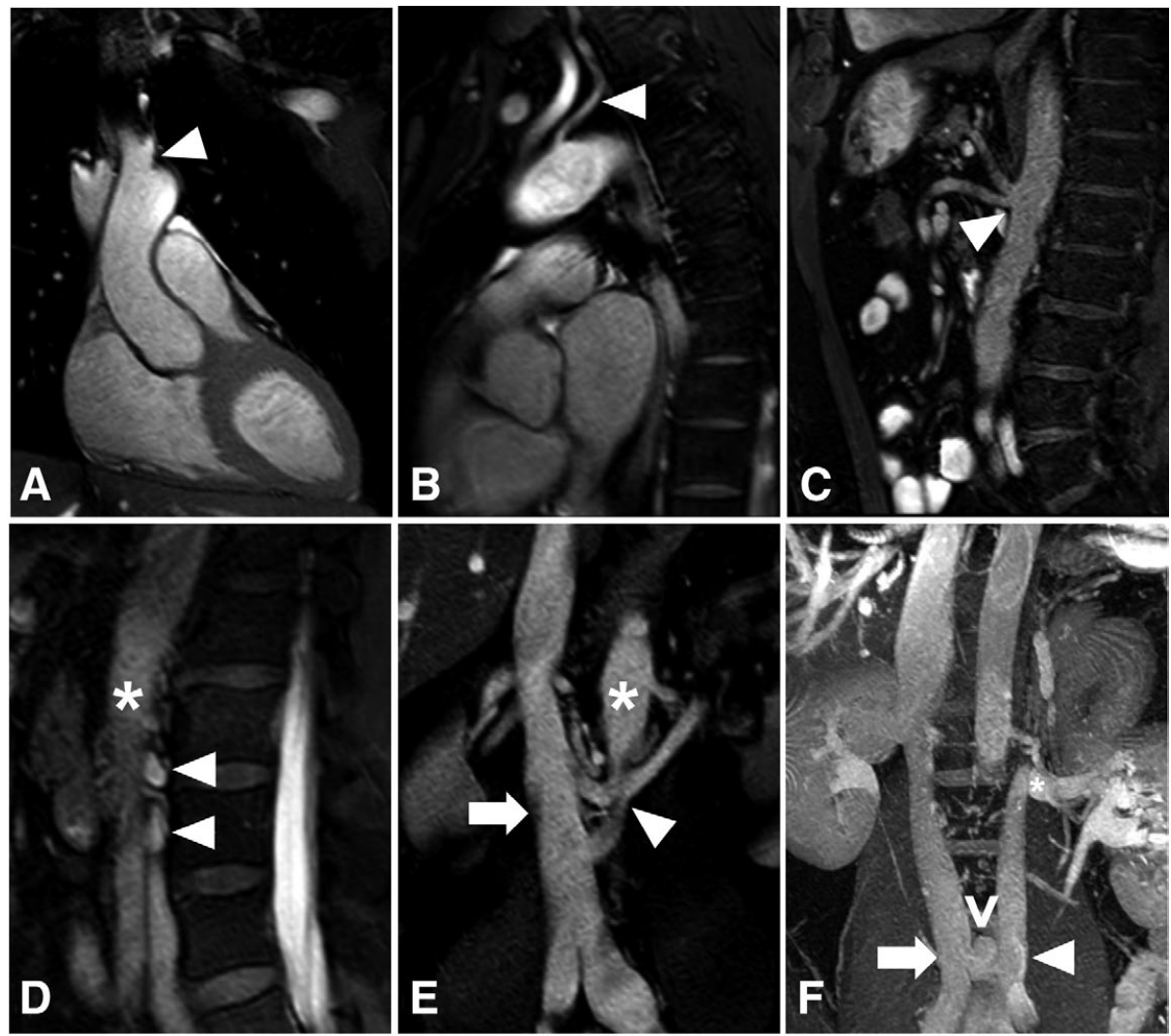

Figure 2. Arterial (Upper) and venous (Lower) anomalies in subjects with thalidomide embryopathy. (A) Coronal image of a bovine arch, (B) sagittal image of a left vertebral artery originating from aortic arch, (C) sagittal image of a coeliac-mesenteric trunk, (D) sagittal image of 2 retroaortic left renal veins (arrowheads), which travel between the spine and the abdominal aorta, (E) coronal image of 2 retroaortic veins (arrowheads), which originate from a single vessel and drain into the inferior vena cava (IVC, arrow). The bifurcation is located dorsal of the abdominal aorta $\left(^{*}\right)$. (F) Volume-rendered image of a duplicated left IVC (arrowhead), which originated from the left renal vein ${ }^{*}$ ). The left IVC has no cranial run off but is connected via a transverse interiliac vein (open arrowhead) to the right IVC (arrow) at the lumbar level. 
Table 2. Types of Arterial Anomalies in Subjects With Inferior Vena Cava and Normal Values From the Literature

\begin{tabular}{|c|c|c|c|c|c|c|}
\hline \multirow[b]{2}{*}{ Arterial anomalies } & \multirow[b]{2}{*}{ Normal value } & \multirow[b]{2}{*}{$\begin{array}{l}\text { Thalidomide } \\
(n=78,100 \%)\end{array}$} & \multicolumn{3}{|c|}{ Dysmelia restricted to } & \multirow{2}{*}{$\begin{array}{c}\text { Eye, ear or } \\
\text { facial damage } \\
(n=21,27 \%)\end{array}$} \\
\hline & & & $\begin{array}{c}\text { Hand } \\
(n=23,29 \%)\end{array}$ & $\begin{array}{c}\text { Forearm } \\
(n=30,38 \%)\end{array}$ & $\begin{array}{c}\text { Upper arm } \\
(n=25,32 \%)\end{array}$ & \\
\hline Bovine arch & $8-27.4^{11,32}$ & $17(22)$ & $3(13)$ & $3(10)$ & $11(44)^{\star \star}$ & $3(14)$ \\
\hline Arteria lusoria & $1-1.2^{11,32}$ & $2(3)$ & $1(4)$ & $1(3)$ & 0 & $1(5)$ \\
\hline Left vertebral artery from aortic arch & $4.1-6.6^{11,32}$ & $9(12)^{*}$ & $4(17)^{\star \star}$ & $3(10)$ & $2(8)$ & $4(19)^{\star \star}$ \\
\hline Coeliomesenteric trunk & $<1^{33}$ & $2(3)$ & 0 & $1(3)$ & $1(4)$ & $1(5)$ \\
\hline Doubled renal arteries & $23^{31}$ & $29(37)^{*}$ & 9 (39) & $9(30)$ & $11(44)$ & 7 (33) \\
\hline Tripled renal arteries & $4^{31}$ & $5(6)$ & $3(13)^{\star \star}$ & $1(3)$ & $1(4)$ & $1(5)$ \\
\hline Renal artery from iliac artery & $0.03-0.05^{31,32}$ & $4(5)$ & $1(4)$ & $3(10)$ & 0 & $2(10)$ \\
\hline Sum & NA & 68 & 21 & 21 & 26 & 19 \\
\hline
\end{tabular}

Data are number $(\mathrm{n})$ and percentage (\%), whereas normal values from the literature are given in percentage (\%) only. ${ }^{*}$ Indicates divergence from reported values in the literature. ${ }^{\star \star}$ Indicates accumulation of anomalies in subgroups. NA, not available.

\begin{tabular}{|c|c|c|c|c|c|c|}
\hline \multirow[b]{2}{*}{ Venous anomalies } & \multirow[b]{2}{*}{ Normal value } & \multirow{2}{*}{$\begin{array}{l}\text { Thalidomide } \\
(n=78,100 \%)\end{array}$} & \multicolumn{3}{|c|}{ Dysmelia restricted to } & \multirow{2}{*}{$\begin{array}{c}\text { Eye, ear or } \\
\text { facial damage } \\
(n=21,27 \%)\end{array}$} \\
\hline & & & $\begin{array}{c}\text { Hand } \\
(n=23,29 \%)\end{array}$ & $\begin{array}{c}\text { Forearm } \\
(n=30,38 \%)\end{array}$ & $\begin{array}{c}\text { Upper arm } \\
(n=25,32 \%)\end{array}$ & \\
\hline Retroaortic left renal vein & $0.8-3.6^{16,17}$ & $12(15)^{*}$ & $3(13)$ & $5(17)$ & $4(16)$ & $4(19)$ \\
\hline Doubled renal veins & $15-30^{31}$ & $11(14)$ & $5(22)$ & $4(13)$ & $2(8)$ & 0 \\
\hline Tripled renal veins & NA & $1(2)$ & 0 & $1(3)$ & 0 & 0 \\
\hline Renal vein draining into common iliac vein & $0.03-0.05^{34,35}$ & $4(5)$ & $1(4)$ & $3(10)$ & 0 & $1(5)$ \\
\hline Duplicated IVC & $0.2-3^{18}$ & $2(3)$ & $2(9)^{\star *}$ & 0 & 0 & $1(5)$ \\
\hline Compression of right common iliac vein & NA & $1(2)$ & $1(4)$ & 0 & 0 & 0 \\
\hline Sum & NA & 31 & 12 & 13 & 6 & 6 \\
\hline
\end{tabular}

Data are number (n) and percentage (\%), whereas normal values from the literature are given in percentage (\%) only. ${ }^{*}$ Indicates divergence from reported values in the literature. ${ }^{* *}$ Indicates accumulation of anomalies in subgroups. NA, not available.

No subject was excluded because of MRA contraindication or claustrophobia. All studies were diagnostic with good to excellent image quality. Image parameters were: TR/TE: 2.6/1.03 ms; flip angle: $60^{\circ}$; SENSE factor 2; field of view: feet-heel $280 \mathrm{~mm}$, right-left: $381 \mathrm{~mm}$, anterior-posterior: $169 \mathrm{~mm}$; matrix: $192 \times 192$; acquired voxel size: $1.2 \times 1.2 \times 4 \mathrm{~mm}$; reconstructed voxel size: $0.6 \times 0.6 \times 4 \mathrm{~mm}$; slice thickness: $4 \mathrm{~mm}$; number of slices: 56 with 8 slices per breath hold, gap: $-1 \mathrm{~mm}$. Scan time was $35-45 \mathrm{~min}$, depending on body size and heart rate.

\section{Vascular and Organ Evaluation Criteria}

Radiologists with 8 and 4 years of experience, respectively, and blinded to the patients' information evaluated the MRA images in consensus according to the following criteria. A normal branching pattern of the aortic arch was defined in the presence of a brachiocephalic trunk, a left common carotid artery and a left subclavian artery. A bovine arch was defined if the left common artery arose from the brachiocephalic trunk. A separate offspring of the left vertebral artery as the last vessel from the aortic arch was defined as anomalous. ${ }^{11}$ A common offspring of both the coeliac and superior mesenteric arteries was defined as a coeliac-mesenteric trunk. ${ }^{12}$ Normal renal vascular anatomy was defined in the presence of 1 renal artery and 1 renal vein on each side arising from or draining into the abdominal aorta or the inferior vena cava (IVC), respectively. Kidneys were considered normal if they were paired and slightly obliquely positioned..$^{13}$

\section{Results}

\section{Vascular and Organ Anomalies}

A total of 115 anomalies were found in 62 of the 78 subjects $(79 \%)$, including 99 vascular anomalies in 58 subjects $(74 \%)$ and 16 organ anomalies in 15 subjects (19\%); 28 subjects $(36 \%)$ had a single vascular or a single organ anomaly, 22 subjects $(28 \%)$ had 2 anomalies, 7 subjects $(9 \%)$ had 3 anomalies, 4 subjects $(5 \%)$ had 4 anomalies and 1 subject $(1 \%)$ had 6 anomalies (Table 1A). Of the 99 vascular anomalies, $68(69 \%)$ were related to the arteries, and 31 were venous anomalies (31\%) (Table 1B). The renal vessels were most frequently involved in 66 of the 99 vascular anomalies $(67 \%)$, followed by the supraaortic arteries with 28 anomalies (28\%) (Table 1B).

\section{Arterial Vascular Anomalies}

A total of 17 subjects had a bovine arch, 2 had an arteria lusoria and 9 had a left vertebral artery originated from the aortic arch (Figure 2). A coelio-mesenteric trunk was found in 2 subjects. Doubled and tripled renal arteries were found in 29 and 5 subjects, respectively (Table 2). The renal artery originated from the common iliac artery in all 4 subjects with a pelvic kidney. Comparison of the observed frequencies with reported frequencies from the literature revealed that subjects with TE more often had a left vertebral artery originating from the aortic arch, doubled renal arteries and a renal artery from an iliac artery (Table 2). Examples of arterial and venous anomalies are shown in Figure 2. 


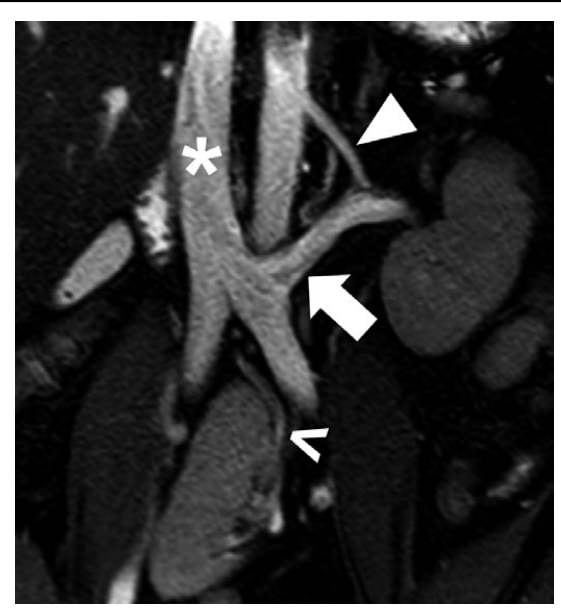

Figure 3. Coronal image of a subject with thalidomide embryopathy and a right pelvic kidney and a normal located left kidney. The renal artery of the right pelvic kidney (open arrowhead) originates from the right iliac artery. The left renal artery (arrowhead) originates from the aorta. A large left renal vein (arrow) drains into the inferior vena cava $\left({ }^{*}\right)$. The right renal vein is not depicted on this image.

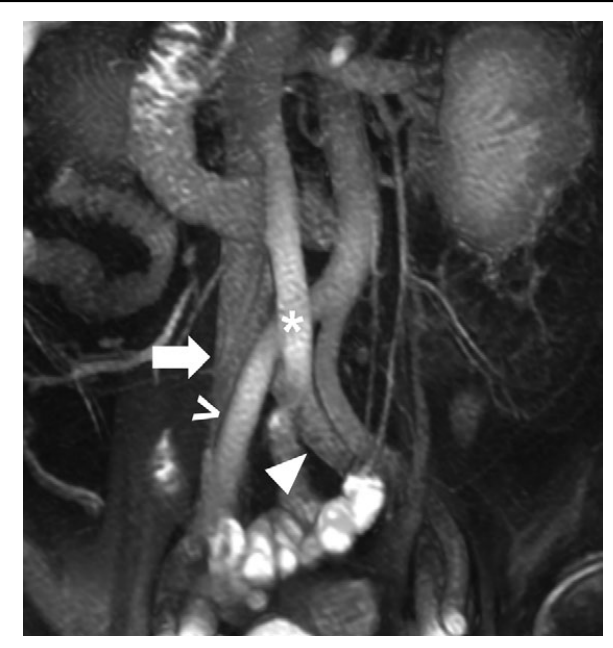

Figure 4. Volume-rendered image of another case of duplicated inferior vena cava (IVC). The left-sided IVC $\left(^{*}\right)$ arises from the common left iliac vein (arrowhead) and is located anterior of the right common iliac artery (open arrowhead). The duplicated left IVC drains into the right IVC (arrow) just below the left renal vein.

Table 4. Types of Organ Anomalies in Subjects With Thalidomide Embryopathy and Normal Values From the Literature

\begin{tabular}{|c|c|c|c|c|c|c|}
\hline \multirow[b]{2}{*}{ Organ anomalies } & \multirow[b]{2}{*}{ Normal value } & \multirow{2}{*}{$\begin{array}{l}\text { Thalidomide } \\
(n=78,100 \%)\end{array}$} & \multicolumn{3}{|c|}{ Dysmelia restricted to } & \multirow{2}{*}{$\begin{array}{l}\text { Eye, ear or } \\
\text { facial damage } \\
(n=21,27 \%)\end{array}$} \\
\hline & & & $\begin{array}{c}\text { Hand } \\
(n=23,29 \%)\end{array}$ & $\begin{array}{c}\text { Forearm } \\
(n=30,38 \%)\end{array}$ & $\begin{array}{c}\text { Upper arm } \\
(n=25,32 \%)\end{array}$ & \\
\hline Single kidney & $0.04^{36}$ & $4(5)^{*}$ & $2(9)$ & $1(3)$ & $1(4)$ & $1(5)$ \\
\hline Pelvic kidney & $0.03-0.05^{31,32}$ & $4(5)^{*}$ & $1(4)$ & $3(10)^{\star \star}$ & 0 & $2(10)^{\star \star}$ \\
\hline Malrotated kidney & NA & $3(4)$ & $2(9)$ & 0 & $1(4)$ & $1(5)$ \\
\hline Duplex kidney & $0.7^{34}$ & $1(1)$ & $1(4)$ & 0 & 0 & $1(5)$ \\
\hline Gallbladder agenesis & $0.01-0.75^{27}$ & $4(5)^{*}$ & 0 & $3(10)^{\star \star}$ & $1(4)$ & $2(10)^{\star *}$ \\
\hline Sum & NA & 16 & 6 & 7 & 3 & 7 \\
\hline
\end{tabular}

Data are number $(\mathrm{n})$ and percentage $(\%)$, whereas normal values from the literature are given in percentage $(\%)$ only. ${ }^{*}$ Indicates divergence from reported values in the literature. ${ }^{\star *}$ Indicates accumulation of anomalies in subgroups. NA, not available.

\section{Venous Vascular Anomalies}

A retroaortic left renal vein was the most frequent venous anomaly, which occurred $15 \%$ more often in subjects with TE compared with the normal value of $0.8-3.6 \%$ (Table 3 ). A total of 11 subjects had doubled renal veins and 1 subject had tripled renal veins. In 3 of the 4 subjects with a pelvic kidney the renal vein drained into the common iliac vein. In the 4th subject, the right renal vein drained into the IVC while the renal vein of the normally located left kidney drained into the common iliac vein (Figure 3); 2 subjects had a duplicated IVC, shown in Figure 2F and Figure 4.

\section{Organ Anomalies}

A total of 15 patients had 16 abdominal organ malformations, including 12 kidney anomalies and 4 cases of gallbladder agenesis. Kidney anomalies included 4 single kidneys ( 1 right, 3 left), 4 pelvic kidneys ( 3 right, 1 left), 3 malrotated kidneys and 1 duplex left-sided kidney with a normal right kidney (Table 4). Of the 4 subjects had a gallbladder agenesis, 1 also had a pelvic kidney. Single, duplex and pelvic kidneys and gallbladder agenesis occurred more often in subjects with TE compared with frequencies in the literature (Table 4).

\section{Association Between Vascular and Organ Anomalies and Extent of Dysmelia}

No specific pattern was found for arterial, venous or organ anomalies with a clear association between the extent of dysmelia and frequency of organ anomalies. However, a bovine arch occurred $44 \%$ most often in subjects with dysmelia of the upper arm, while a left vertebral artery originating from the aortic arch $(17 \%)$ and tripled renal arteries $(13 \%)$ occurred more often in subjects with dysmelia of the hand (Table 2). A duplicated IVC occurred only in subjects with dysmelia of the hand (Table 3). Pelvic kidneys and gallbladder agenesis occurred more often in subjects with dysmelia of the forearm (Table 4).

\section{Association Between Vascular and Organ Anomalies and Eye, Ear or Facial Anomalies}

A left vertebral artery originating from the aortic arch, pelvic kidneys and gallbladder agenesis seemed to occur more in subjects with eye, ear or facial anomalies (Tables 2,4). Other than these anomalies, there was no 
clear association between vascular and organ anomalies and eye, ear or facial anomalies.

\section{Renal Function in Subjects With TE}

All subjects had normal creatinine and normal eGFR data. Mean serum creatinine and eGFR were in the normal range at $0.77 \pm 0.18 \mathrm{mg} / \mathrm{dL}$ and $93 \pm 11 \mathrm{~mL} / \mathrm{min}$, respectively. All subjects with a retroaortic left renal vein had similar serum creatinine and eGFR levels of $0.83 \pm 0.2 \mathrm{mg} / \mathrm{dL}$ and $92 \pm 13 \mathrm{~mL} / \mathrm{min}$, respectively, compared with 50 subjects without a retroaortic renal vein or renal malformation who had $0.77 \pm 0.18 \mathrm{mg} / \mathrm{dL}$ and $94 \pm 11 \mathrm{~mL} / \mathrm{min}$, respectively. Serum creatinine and eGFR data were available in 11 of the 12 subjects with kidney malformations, and were normal at $0.78 \pm 0.11 \mathrm{mg} / \mathrm{dL}$ and with $94 \pm 8 \mathrm{~mL} / \mathrm{min}$, respectively. Of 39 subjects with available urine albumin data, $34(87 \%)$ had normoalbuminuria of $5.9 \pm 2.6 \mathrm{mg} / \mathrm{g}$ (range: $2-12 \mathrm{mg} / \mathrm{g}$ ) and 5 had microalbuminuria of $74 \pm 59 \mathrm{mg} / \mathrm{g}$ (range: $31-177 \mathrm{mg} / \mathrm{g}$ ). None of the subjects had macroalbuminuria. Of the 5 subjects with microalbuminuria 2 had diabetes type II and arterial hypertension, 2 had arterial hypertension and 1 subject had neither diabetes nor arterial hypertension, but a malrotated kidney.

\section{Discussion}

We successfully determined the frequency of vascular and organ malformations in asymptomatic adults with TE using non-contrast MRA. We also analyzed the effect of the observed malformations on renal function and compared the observed frequencies with reported values from the literature. The main findings of our study were as follows. (1) Vascular anomalies were found in 74\% of the study subjects with TE. (2) Two-thirds of the vascular anomalies were related to the arteries and one-third to the veins. Most of the vascular anomalies were within reported frequencies; however, supernumerary renal arteries, left vertebral artery originating from aortic arch and a retroaortic left renal vein occurred more often in subjects with TE than previously reported. (3) Subjects with TE also had abdominal organ anomalies, most often involving the renal system with single, pelvic, duplicated and malrotated kidneys. (4) We found no evidence that the observed vascular or organ malformations had affected renal function in the current study's long-term survivors with TE. However, knowledge about possible malformations is important for subjects with TE in case of future abdominal surgical or vascular treatment.

\section{Effect of Thalidomide on the Vascular and Renal Systems}

Our findings suggested that thalidomide had mainly affected renal vessels, because we found the largest variations from reported normal values in the number of renal arteries and in the retroaortic course of the left renal vein. Because we did not have any information about the time point and frequency of maternal thalidomide intake during pregnancy, we cannot draw any direct conclusions about the sensitive period of this drug. However, embryological studies may give some clues. During weeks 6 and 9 of human embryological development the kidneys ascend from an initial sacral level to a final position at the upper lumbar level. This ascent of the kidneys is paralleled by development of transitory arterial vessels, which originate from the aorta. The final renal arteries arise from the lumbar part of the aorta, while the transitory vessels usually disap- pear. ${ }^{14}$ Hypotheses suggests that renal malposition with pelvic kidneys might be related to persistent transitory vessels, which physically block the ascent of the kidneys from the pelvis to its normal lumbar position. ${ }^{\mathbf{1 4 , 1 5}}$ Our observation that all 4 renal arteries and 3 renal veins in the 4 subjects with pelvic kidneys originated from the common iliac artery or iliac veins fits with this hypothesis.

Embryological studies also indicate that improper completion of the complex embryological development of the retroperitoneal venous system can result in malformations of the renal veins and the IVC. ${ }^{16}$ A retroaortic left renal vein was the most frequent venous malformation in subjects with TE and showed the highest difference to reported values. ${ }^{16,17}$ One potential explanation could be that thalidomide prevented normal regression of the circumaortic venous plexus, resulting in displacement of the left renal vein. We found 2 cases of IVC duplication, which is within the range of reported frequencies. ${ }^{18}$ However, the anatomic course of the observed IVC duplications did not match commonly known IVC duplications. ${ }^{19}$ According to a proposed classification the duplicated left-sided IVC drains into the left renal vein, which drains into the right sided IVC. ${ }^{19}$ Both of the present cases of IVC duplication had distinctly different drainage. In 1 subject, the left renal vein drained into the duplicated left IVC, which was transversely connected to the right IVC at the lower lumbar level. In the second subject, the left IVC arose from the left common iliac vein, located anterior of the right common iliac artery, and drained into the right IVC just below the left renal vein. These 2 cases suggest that thalidomide resulted in unusual, currently unknown IVC duplications.

\section{Effect of Thalidomide on Abdominal Organs}

We only observed malformations of the abdominal organs, mainly the kidneys, which including single, duplicated, malrotated and malpositioned kidneys. Furthermore, 4 subjects had gallbladder agenesis. These findings in adult subjects with TE are less severe than the early postmortem examinations and clinical studies of children with TE from the 1960s, which included abdominal malformations such as duodenal atresia and anteriorly displaced anal orifices requiring surgical intervention. ${ }^{20-22}$

\section{Possible Molecular Pathway of Thalidomide Teratogenesis} The teratogenic effects of thalidomide has been have been recently discovered. ${ }^{23,24}$ Eichner et al showed that both the antiangiogenic and teratogenic effects of thalidomide were exerted via the protein cereblon. In a zebrafish model thalidomide binds to and inhibits cereblon, which is essential for a complex developmental cascade resulting in limb outgrowth and expression of the fibroblast growth factor $8 .{ }^{24}$ Eichner et al demonstrated that thalidomide inhibited vasculogenesis, which was preceded by reduced expression of fibroblast growth factor 8 and cell death in the limb buds, resulting in decreased size of the head and eyes. Furthermore, it was shown that loss of fibroblast growth factor 8 function led to development abnormalities of the brain and kidneys. ${ }^{25}$ Even though the described pathways may not be entirely reproducible in humans, it might explain the frequent vascular, kidney, auditory and facial malformations found in the current study.

\section{Clinical Consequences of the Observed Anomalies}

A previous study suggested that a retroaortic course of the left renal vein can lead to increased pressure in the renal 
vein because of the compression of this vessel between the aorta and the spine. ${ }^{26}$ Furthermore, it was postulated that this venous congestion resulted in proteinuria. ${ }^{26}$ However, all our subjects with a retroaortic left vein had normal serum creatinine levels and none had microalbuminuria. In 4 of the 5 subjects with microalbuminuria, there was no evidence of either diabetes type II or arterial hypertension, which would be the most likely causes for microalbuminuria in these subjects. ${ }^{27}$ Knowledge of the anatomy of the abdominal organs and vessels is important for any invasive or minimally invasive surgical procedure in this region..$^{\mathbf{2 8}, 29}$ A study of the surgical repair of abdominal aneurysms reported a high incidental injury rate of retroaortic left renal veins during surgery, which led to nephrectomy and death in 2 cases each. ${ }^{29}$ Thus, the course of the renal vein and presence of a doubled IVC is important information with regard to any surgical intervention of the abdominal aorta, because incidental injury of these vessels is a severe surgical complication. A case report highlighted the importance of exact preoperative knowledge of the patient's anatomy; ${ }^{30}$ in this case the patient presented with symptoms mimicking gallbladder pathology, which resulted in an attempted, but unsuccessful laparoscopic cholecystectomy. Postoperative MR imaging confirmed gallbladder agenesis, which in retrospect made the surgical intervention unnecessary. This unwanted outcome could have been avoided by timely use of imaging. Therefore, we recommend preoperative imaging of the abdominal organs and vessels in any subject with TE, preferably non-contrast MRA to accurately depict any anomalies and to plan the operative strategy.

\section{Study Limitations}

First, the number of subjects was relative small, but this was the first systematic study of vascular and organ malformations in subjects with TE. Second, we did not have a control group to analyze the normal frequencies of the observed malformations. To overcome this limitation, we compared the observed frequencies with reported normal values in the literature. This approach is limited, because the reported normal values were obtained within the past 4 decades using different techniques such as postmortem autopsies, venography and computed tomography. These variable reference methods possibly resulted in inconsistent findings. Furthermore, no information was available in the cited literature about the combined occurrence of vascular and organ anomalies or of vascular anomalies in different anatomic locations, such as supraaortic and renal vessel anomalies. ${ }^{11,16-18,30-37}$ Based on the current findings we calculated a sample size of 400 subjects with TE and 400 controls to show significant differences in frequent malformations such as a retroaortic left renal vein. Third, our data most likely represented a positive selection of subjects with less severe TE because we only studied subjects with $\mathrm{TE}$ and dysmelia restricted to the upper limbs. It is possible that subjects with malformations of the lower extremities have more profound vascular and organ anomalies. Furthermore, our study population was biased because we studied subjects with TE who had survived $>50$ years, representing a positive selection of our population.

\section{Conclusion}

Non-contrast MRA revealed a high number of vascular and abdominal organ anomalies in subjects with TE. All subjects with vessel or kidney anomalies had normal renal function, suggesting a benign nature of these malformations in the current study's long-term survivors with TE. Nevertheless, the current findings are essential for any physician who is involved in the patient care of subjects with TE. We recommend preoperative imaging of the abdominal vessels and organs in subjects with TE scheduled for surgery, preferably by non-contrast MRA to depict the anatomy and to plan the operative strategy.

\section{Disclosures}

U.W. is an employee of Philips Healthcare, Hamburg, Germany. The other authors report no conflicts.

\section{References}

1. Lenz W. A short history of thalidomide embryopathy. Teratology 1988; 38: 203-215.

2. Matthews SJ, McCoy C. Thalidomide: A review of approved and investigational uses. Clin Ther 2003; 25: 342-395.

3. Peters KM, Albus C, Lüngens M, Niecke A, Pfaff H, Samel C. Damage to health, psychosocial disorders and care requirements of thalidomide survivors in North Rhine Westphalia from a long-term perspective. Expert Opinion commissioned by LZG. NRW. Bielefeld: Federal Health Centre North Rhine Westphalia (LZG.NRW), 2016.

4. Sales Luiz Vianna F, Kowalski TW, Fraga LR, Sanseverino MTV, Schuler-Faccini L. The impact of thalidomide use in birth defects in Brazil. Eur J Med Genet 2017; 60: $12-15$.

5. Kruse A, Ding-Greiner C, Stolla C. Expertise über die Leistungen an Leistungsberechtigte nach dem Contergan-stiftungsgesetz Bericht an die Conterganstiftung für behinderte Menschen. 2016; 1-95 (in German).

6. Tajima T, Wada T, Yoshizawa A, Masuda T, Okafuji T, Nakayama $\mathrm{T}$, et al. Internal anomalies in thalidomide embryopathy: Results of imaging screening by CT and MRI. Clin Radiol 2016; 71: 1199.e1-1199.e7.

7. Bannas P, François CJ, Reeder SB. Magnetic resonance angiography of the upper extremity. Magn Reson Imaging Clin North Am 2015; 23: 479-493.

8. Krishnam MS, Tomasian A, Malik S, Desphande V, Laub G, Ruehm SG. Image quality and diagnostic accuracy of unenhanced SSFP MR angiography compared with conventional contrastenhanced MR angiography for the assessment of thoracic aortic diseases. Eur Radiol 2009; 20: 1311-1320.

9. KDIGO. 2012 Clinical Practice Guideline for the Evaluation and Management of Chronic Kidney Disease. 2012; 1-163.

10. Lenz W. The sensitivity period of thalidomide embryopathy in monkeys and humans. Dtsch Med Wochenschr 1967; 92: 2186 2187.

11. Müller M, Schmitz BL, Pauls S, Schick M, Röhrer S, Kapapa T, et al. Variations of the aortic arch: A study on the most common branching patterns. Acta Radiol 2011; 52: 738-742.

12. White RD, Weir-McCall JR, Sullivan CM, Mustafa SA, Yeap PM, Budak MJ, et al. The celiac axis revisited: Anatomic variants, pathologic features, and implications for modern endovascular management. Radiographics 2015; 35: 879-898.

13. Quaia E, Martingano P, Cavallaro M, Premm M, Angileri R. Normal radiological anatomy and anatomical variants of the kidney. In: Quaia E, editor. Radiological imaging of the kidney. 2nd edn. Heidelberg: Springer, 2014; 17-74.

14. Cinman NM, Okeke Z, Smith AD. Pelvic kidney: Associated diseases and treatment. $J$ Endourol 2007; 21: 836-842.

15. Malek RS, Kelalis PP, Burke EC. Ectopic kidney in children and frequency of association with other malformations. Mayo Clin Proc 1971; 46: 461-467.

16. Karkos CD, Bruce IA, Thomson GJL, Lambert ME. Retroaortic left renal vein and its implications in abdominal aortic surgery. Ann Vasc Surg 2001; 15: 703-708.

17. Karaman B, Koplay M, Özturk E, Basekim CC, Ogul H, Mutlu $\mathrm{H}$, et al. Retroaortic left renal vein: Multidetector computed tomography angiography findings and its clinical importance. Acta Radiol 2007; 48: 355-360.

18. Bass JE, Redwine MD, Kramer LA, Huynh PT, Harris JH Jr. Spectrum of congenital anomalies of the inferior vena cava: Cross-sectional imaging findings 1. Radiographics 2000; 20: 639652. 
19. Morita S, Higuchi M, Saito N, Mitsuhashi N. Pelvic venous variations in patients with congenital inferior vena cava anomalies: Classification with computed tomography. Acta Radiol 2007; 48: 974-979.

20. Leck IM, Millar EL. Incidence of malformations since the introduction of thalidomide. $B M J 1962 ; 2$ : 16-20.

21. Ciciliani J, Tolks H. Ergebnisse systematischer Untersuchungen bei 96 Dysmeliekindern: Results of systematic studies of 96 dysmelia children. Med Welt 1966; 43: 2301-2307.

22. Smithells RW, Newman CG. Recognition of thalidomide defects. Am J Med Genet 1992; 29: 716-723.

23. Eichner R, Heider M, Fernández-Sáiz V, van Bebber F, Garz $\mathrm{AK}$, Lemeer $\mathrm{S}$, et al. Immunomodulatory drugs disrupt the cereblon-CD147-MCT1 axis to exert antitumor activity and teratogenicity. Nat Med 2016; 22: 735-743.

24. Ito T, Hideki A, Suzuki T, Ogura T, Hotta K, Imamura Y, et al. Identification of a primary target of thalidomide teratogenicity. Science 2010; 327: 1345-1350.

25. Grieshammer U, Cebrián C, Ilagan R, Meyers E, Herzlinger D, Martin GR. FGF8 is required for cell survival at distinct stages of nephrogenesis and for regulation of gene expression in nascent nephrons. Development 2005; 132: 3847-3857.

26. Cuéllar i Calàbria $\mathrm{H}$, Quiroga Gómez $\mathrm{S}$, Sebastià Cerqueda $\mathrm{C}$, Boyé de la Presa R, Miranda A, Àlvarez-Castells A. Nutcracker or left renal vein compression phenomenon: Multidetector computed tomography findings and clinical significance. Eur Radiol 2005; 15: 1745-1751.

27. Basi S, Fesler P, Mimran A, Lewis JB. Microalbuminuria in type 2 diabetes and hypertension: A marker, treatment target, or innocent bystander? Diabetes Care 2008; 31(Suppl 2): S194-S201.

28. Bartle EJ, Pearce WH, Sun JH, Rutherford RB. Infrarenal venous anomalies and aortic surgery: Avoiding vascular injury. J Vasc Surg 1987; 6: 590-593.
29. Brener BJ, Darling RC, Frederick PL, Linton RR. Major venous anomalies complicating abdominal aortic surgery. Arch Surg 1974; 108: 159-165.

30. Balakrishnan S, Singhal T, Grandy-Smith S, El-Hasani S. Agenesis of the gallbladder: Lessons to learn. JSLS 2006; 10: $517-519$.

31. Türkvatan A, Özdemir M, Cumhur T, Ölçer T. Multidetector CT angiography of renal vasculature: Normal anatomy and variants. Eur Radiol 2008; 19: 236-244.

32. Berko NS, Jain VR, Godelman A, Stein EG, Ghosh S, Haramati LB. Variants and anomalies of thoracic vasculature on computed tomographic angiography in adults. $J$ Comput Assist Tomogr 2009; 33: 523-528.

33. Winston CB, Lee NA, Jarnagin WR, Teitcher J, DeMatteo RP, Fong Y, et al. CT angiography for delineation of celiac and superior mesenteric artery variants in patients undergoing hepatobiliary and pancreatic surgery. Am J Roentgenol 2007; 189: W13-W19.

34. Perlmutter AD, Retik AB, Bauer SB. Anomalies of the upper urinary tract. In: Walsh PC, Gittes, RF, Perlmutter AD, et al, editors. Campbell's urology. 5th edn. Philadelphia: WB Saunders, $1986 ; 1665$.

35. Zafar FS, Lingeman JE. Value of laparoscopy in the management of calculi complicating renal malformations. J Endourol 1996; 10: 379-383.

36. Laurichesse Delmas H, Kohler M, Doray B, Lémery D, Francannet $\mathrm{C}$, Quistrebert J, et al. Congenital unilateral renal agenesis: Prevalence, prenatal diagnosis, associated anomalies: Data from two birth-defect registries. Birth Defects Res 2017; 109: $1204-1211$.

37. Gay SB, Armistead JP, Weber ME, Williamson BR. Left infrarenal region: Anatomic variants, pathologic conditions, and diagnostic pitfalls. Radiographics 1991; 11: 549-570. 